\title{
A RANDOMISED CLINICAL TRIAL COMPARING THE EFFICACY AND SAFETY OF ROPIVACAINE 0.75\% ALONE AND IN COMBINATION WITH DEXMEDETOMIDINE IN EPIDURAL ANAESTHESIA FOR LOWER LIMB SURGERIES
}

\author{
Piyush C. Karande1, Naseema V. Kanase2, Parbati B. Jamale3, Vithal K. Dhulkhed ${ }^{4}$ \\ ${ }^{1}$ Assistant Professor, Department of Anaesthesiology, Krishna Institute of Medical Sciences Deemed University, Karad. \\ 2Professor, Department of Anaesthesiology, Krishna Institute of Medical Sciences Deemed University, Karad. \\ 3 Professor, Department of Anaesthesiology, Krishna Institute of Medical Sciences Deemed University, Karad. \\ ${ }^{4}$ Professor and HOD, Department of Anaesthesiology, Krishna Institute of Medical Sciences Deemed University, Karad.
}

ABSTRACT
TIM
This study was aimed to study the efficacy and safety of ropivacaine alone and in combination with dexmedetomidine in epidural
anaesthesia in patients undergoing lower limb surgeries.

\section{MATERIALS AND METHODS}

A randomised study was conducted on 80 patients at Krishna Hospital, Karad, on those patients undergoing limb surgeries and efficacy of ropivacaine $(0.75 \%)$ and ropivacaine with dexmedetomidine was compared. Eighty patients belonging to ASA physical status 1-2 were selected for the study and randomly allocated to two groups of 40 each, Ropivacaine (RN) group and Ropivacaine + Dexmedetomidine (RD) group. Group RN received $16 \mathrm{~mL}$ of $0.75 \%$ ropivacaine. Group RD received $16 \mathrm{~mL}$ of $0.75 \%$ ropivacaine + Dexmedetomidine.

\section{RESULTS}

The mean time of onset of sensory blockade in group RD was $1.73 \pm 0.73 \mathrm{~min}$ and group RN was $2.43 \pm 1.07$ min. Onset of sensory blockade was clinically faster in group RD ( $<<004)$. The range of block in group RD was T10-T4 and in group RN was T10-T5 and was clinically and statistically not significant. The mean duration of analgesia in group RN was $205.53 \pm 36.36$ min and group RD was $217.2 \pm 48.69 \mathrm{~min}$. The duration of motor block in group RD was $195.83 \pm 29.24$ mins and group RN was $187.26 \pm 33.75$ min. Changes in haemodynamic parameters were not clinically significant.

\section{CONCLUSION}

This randomised, double blinded, clinical trial shows that ropivacaine $0.75 \%$ combined with dexmedetomidine in epidural anaesthesia provides faster onset of sensory block and longer duration of motor block compared to plain ropivacaine $0.75 \%$.

\section{KEYWORDS}

Epidural, Ropivacaine, Dexmedetomidine.

HOW TO CITE THIS ARTICLE: Karande PC, Kanase NV, Jamale PB, et al. A randomised clinical trial comparing the efficacy and safety of ropivacaine $0.75 \%$ alone and in combination with dexmedetomidine in epidural anaesthesia for lower limb surger ies. J. Evolution Med. Dent. Sci. 2016;5(77):5750-5754, DOI: 10.14260/jemds/2016/1296

\section{INTRODUCTION}

Epidural anaesthesia is one of the most common regional anaesthetic techniques used for lower abdominal and lower limb surgeries. The advantages of epidural anaesthesia being

1. It provides effective surgical anaesthesia.

2. It can meet the extended duration of surgical needs.

3. It provides good postoperative analgesia.

4. It reduces incidence of haemodynamic changes with segmental blockade.

Different local anaesthetics are used for epidural anaesthesia, most popular in India being lignocaine and bupivacaine. Lignocaine has intermediate duration of action. Bupivacaine is clinically available as a racemic mixture of the

Financial or Other, Competing Interest: None.

Submission 11-04-2016, Peer Review 12-05-2016,

Acceptance 17-05-2016, Published 26-09-2016.

Corresponding Author:

Dr. Piyush C. Karande,

\#4, Hrishikesh Appartment

Uttekarnagar,

Sadar Bazaar, Satara,

Maharashtra.

E-mail: drpiyushkarande@gmail.com

DOI: $10.14260 /$ jemds/2016/1296 enantiomers. The enantiomers of a chiral drug may vary in their pharmacokinetics, pharmacodynamics, and toxicity. Administering a racemic mixture is in reality administration of two different drugs (Ehrlich, 1992). ${ }^{1}$

A newly introduced long-acting amide linked local anaesthetic, bupivacaine congener "ROPIVACAINE" registered for use in 1996 (White side J B 2001),2 but registered for use in India in 2009 only. Ropivacaine is a pure 'S' enantiomer with low lipid solubility, which blocks nerve fibers involved in pain transmission (A Delta and C Fibers). Ropivacaine has less motor blockade and shorter duration of action than bupivacaine. (Scott et al 1995; Markham et al 1996, Zaric et al 1996).3,4,5

Dexmedetomidine, a highly selective $\alpha-2$ adrenoceptor agonist is the most recent and advanced agent. It has sedative, analgesic, haemodynamic stabilising effects in addition to reduction of anaesthetic drug requirement. 6

As the combination of these two drugs is not extensively studied yet here is an attempt to study the synergistic effect, efficacy, and safety between dexmedetomidine and ropivacaine $0.75 \%$ in epidural anaesthesia and comparing this with $0.75 \%$ ropivacaine alone. 


\section{METHODS}

After obtaining ethical committee approval and informed written consent, 80 patients were randomly selected of age between 18-60 years of age, ASA 1-2, and scheduled for lower limb surgeries. Inclusion criteria were patients of ASA physical status I-II aged between 18 to 70 years of either sex. Exclusion criteria were patients with physical status of ASA III or greater, uncooperative patients, previous spinal surgeries, spine deformities, local site infection, and coagulation abnormalities, allergy to local anaesthetics (Amide group), neuromuscular diseases, patients with poorly-controlled hypertension, patients with haematological disease, neurologic, psychiatric disease, severe renal or hepatic derangement, and patients with history of drug abuse. Group RN received $16 \mathrm{~mL}$ of $0.75 \%$ ropivacaine. Group $\mathrm{RD}$ received $16 \mathrm{~mL}$ of $0.75 \%$ ropivacaine + dexmedetomidine.

Either group received $16 \mathrm{~mL}$ of the respective local anaesthetic agent via epidural catheter. Preoperative assessment was done for each patient and written consent was taken. Intravenous line obtained with 18G cannula and preloaded with RL $500 \mathrm{~mL}$ half an hour before anaesthesia. Basal vital parameters like heart rate, blood pressure, SpO2 were noted. Patients were placed in flexed lateral positions. Epidural space was identified with loss of resistance to air technique using 18G Tuohy epidural needle at L2-3/L3-4 level. An epidural catheter was advanced in cephalad direction into the epidural space and fixed in the space for 3$5 \mathrm{cms}$. Test dose of $3 \mathrm{~mL}$ of $2 \%$ lignocaine with adrenaline $(1: 2,00,000)$ given after negative aspiration of CSF and blood. After confirming the correct position of the catheter, patient will be turned to supine position. Five minutes after test dose in the absence of any adverse squeal, $16 \mathrm{~mL}$ of study drug as per randomisation was given.

\section{RESULTS}

\section{Comparison of Sensory Onset in Patients Studied}

\begin{tabular}{|c|c|c|c|}
\hline & Group RN & Group RD & P Value \\
\hline $\begin{array}{c}\text { Onset of sensory } \\
\text { block to T10 } \\
\text { dermatome } \\
\text { (mins) }\end{array}$ & $14.182 \pm 6.020$ & $12.536 \pm 4.172$ & 0.115 \\
\hline
\end{tabular}

\section{Comparison of Sensory Onset in Patients Studied}

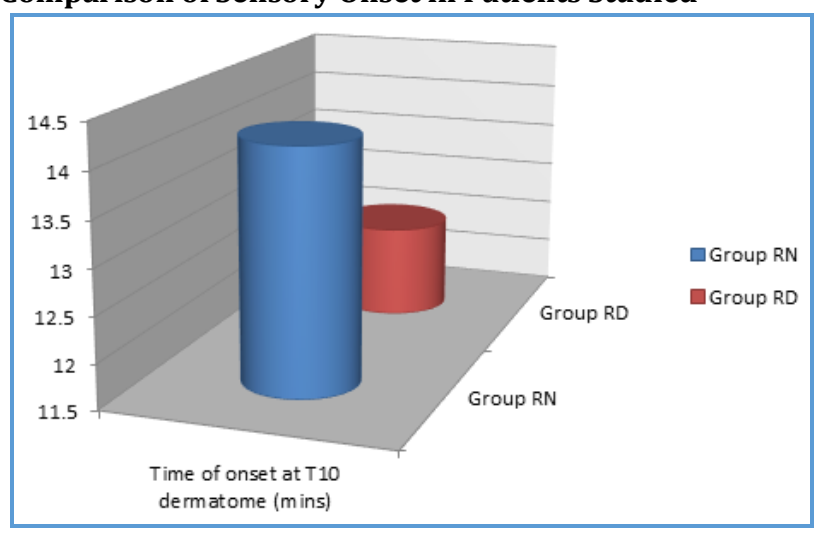

Comparison of Maximum Sensory Level of Patients Studied

\begin{tabular}{|c|c|c|}
\hline Sensory Level & Group RN & Group RD \\
\hline T10 & $4(10.0 \%)$ & $4(10.0 \%)$ \\
\hline T9 & $3(7.5 \%)$ & $3(7.5 \%)$ \\
\hline T8 & $8(20.0 \%)$ & $3(7.5 \%)$ \\
\hline T7 & $6(15.0 \%)$ & $4(10.0 \%)$ \\
\hline T6 & $14(35.0 \%)$ & $8(20.0 \%)$ \\
\hline T4 & $3(7.5 \%)$ & $18(45.0 \%)$ \\
\hline
\end{tabular}

Comparison of Maximum Sensory Level of Patients Studied

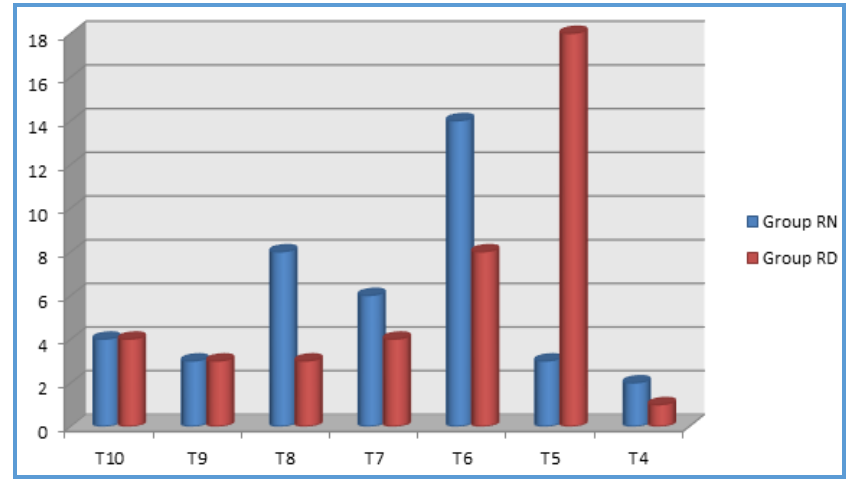

Comparison for Duration for Maximum Sensory Level Reached

\begin{tabular}{|c|c|c|c|}
\hline & Group RN & Group RD & $\begin{array}{c}\text { P } \\
\text { Value }\end{array}$ \\
\hline $\begin{array}{c}\text { Duration of } \\
\text { analgesia (min) }\end{array}$ & $375.20 \pm 15.97$ & $535.18 \pm 19.85$ & 0.000 \\
\hline
\end{tabular}

Comparison for Duration for Maximum Sensory Level Reached

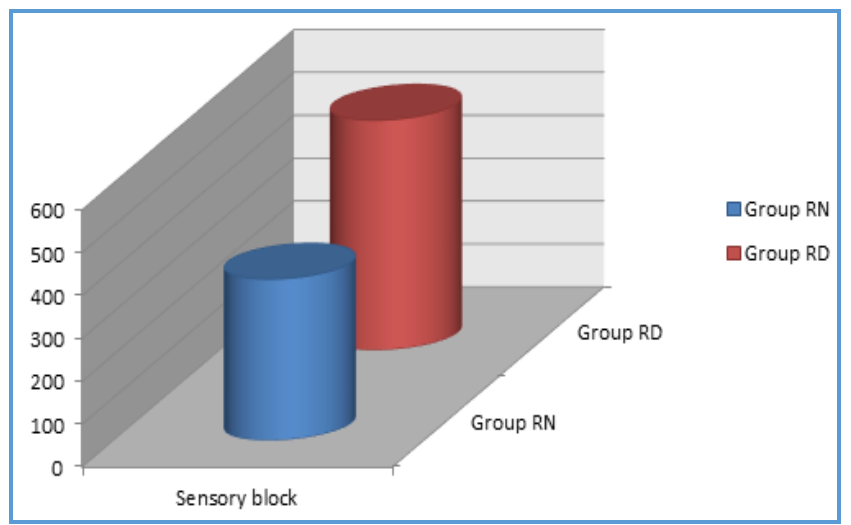

Time to Complete Motor Block

\begin{tabular}{|c|c|c|c|}
\hline & Group RN & Group RD & $\begin{array}{c}\text { P } \\
\text { Value }\end{array}$ \\
\hline $\begin{array}{c}\text { Complete motor } \\
\text { block time (min) }\end{array}$ & $27.34 \pm 5.970$ & $25.73 \pm 4.172$ & 0.123 \\
\hline
\end{tabular}


Time to Complete Motor Block

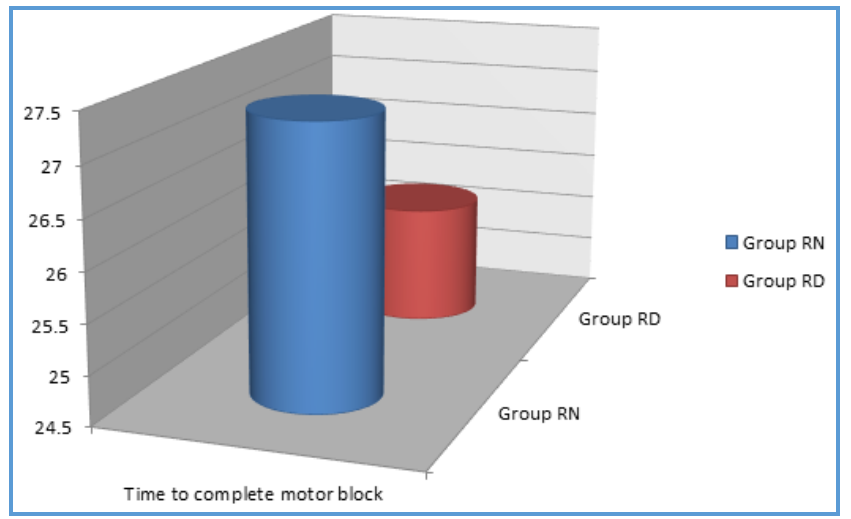

Duration of Motor Block

\begin{tabular}{|c|c|c|c|}
\hline & Group RN & Group RD & $\begin{array}{c}\text { P } \\
\text { Value }\end{array}$ \\
\hline $\begin{array}{c}\text { Duration of } \\
\text { Motor block } \\
\text { (min) }\end{array}$ & $259.80 \pm 15.486$ & $385.92 \pm 17.719$ & 0.000 \\
\hline
\end{tabular}

\section{Duration of Motor Block}

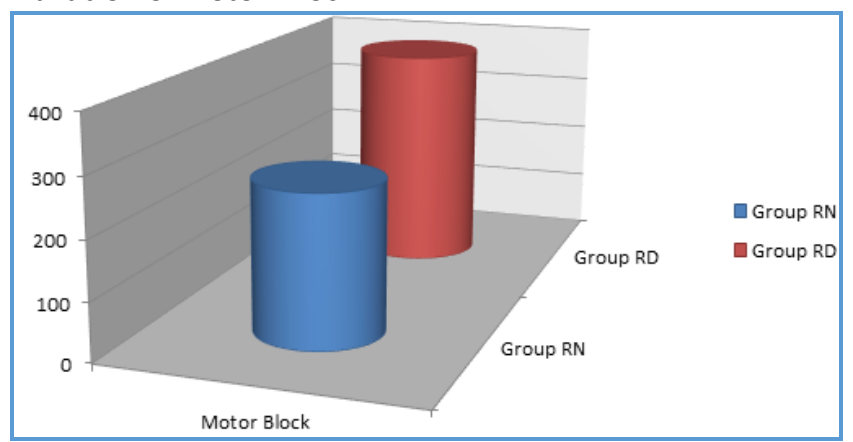

Comparison of Degree of Motor Blockade

\begin{tabular}{|c|c|c|c|}
\hline Bromage & Group RN & Group RD & P Value \\
\hline 0 degree & 0 & 0 & \multirow{2}{*}{0.75} \\
1 degree & 0 & 0 & \\
\hline 2 degree & 11 & 14 & \\
\hline 3 degree & 29 & 26 & \\
\hline
\end{tabular}

Comparison of Degree of Motor Blockade

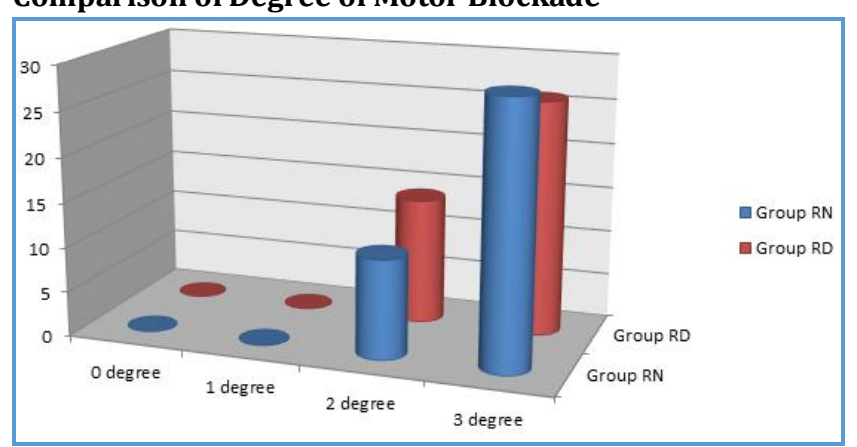

Comparison of Heart Rate (BPM) in two Groups of Patients

\begin{tabular}{|c|c|c|c|}
\hline Heart Rate & Group RN & Group RD & P Value \\
\hline BASAL & $86.66 \pm 8.71$ & $85.3 \pm 13.39$ & 0.641 \\
\hline 0 & $84.16 \pm 8.23$ & $84.9 \pm 13.45$ & 0.799 \\
\hline 5 & $81.86 \pm 7.15$ & $83.73 \pm 13.86$ & 0.514 \\
\hline 10 & $80.2 \pm 6.54$ & $78.03 \pm 9.68$ & 0.314 \\
\hline 20 & $76.58 \pm 12.20$ & $77.2 \pm 9.16$ & 0.535 \\
\hline 30 & $76.66 \pm 6.02$ & $75.9 \pm 8.16$ & 0.680 \\
\hline
\end{tabular}

\begin{tabular}{|c|c|c|c|}
\hline 40 & $76.1 \pm 5.79$ & $75.46 \pm 7.67$ & 0.719 \\
\hline 50 & $76.36 \pm 5.56$ & $75.6 \pm 7.68$ & 0.659 \\
\hline 60 & $76.16 \pm 4.96$ & $75.13 \pm 7.49$ & 0.531 \\
\hline 70 & $76.46 \pm 5.27$ & $74.23 \pm 7.60$ & 0.191 \\
\hline 80 & $76.2 \pm 4.75$ & $74.16 \pm 7.30$ & 0.206 \\
\hline 90 & $77.13 \pm 6.22$ & $74.36 \pm 7.08$ & 0.113 \\
\hline
\end{tabular}

Comparison of Heart Rate (BPM) in Two Groups of Patients

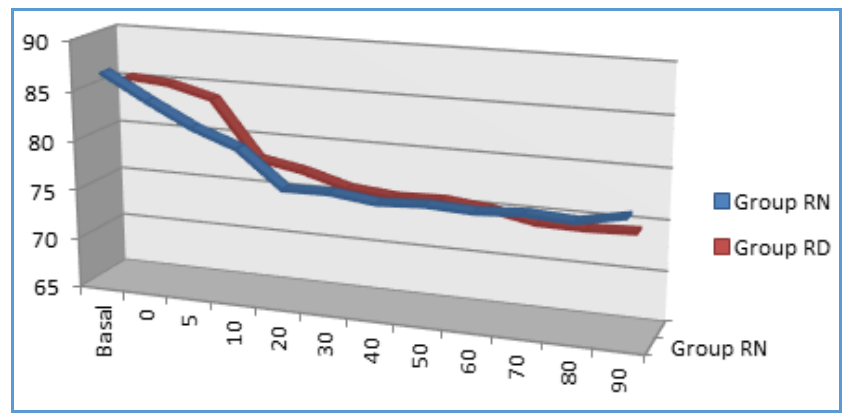

Comparison of Systolic Blood Pressure between Two Groups

\begin{tabular}{|c|c|c|c|}
\hline SBP (mmHg) & Group RN & Group RD & P Value \\
\hline BASAL & $125 \pm 10.38$ & $124.56 \pm 14.36$ & 0.893 \\
\hline 0 & $122 . \pm 11.32$ & $122.3 \pm 13.39$ & 0.925 \\
\hline 5 & $120.33 \pm 11.40$ & $120.26 \pm 13.40$ & 0.98 \\
\hline 10 & $118.43 \pm 11.48$ & $118.73 \pm 11.99$ & 0.921 \\
\hline 20 & $116.33 \pm 11.60$ & $117.4 \pm 10.11$ & 0.705 \\
\hline 30 & $113.46 \pm 11.77$ & $114.76 \pm 10.03$ & 0.646 \\
\hline 40 & $112.96 \pm 11.13$ & $114.13 \pm 8.79$ & 0.654 \\
\hline 50 & $112.63 \pm 10.59$ & $113.43 \pm 7.92$ & 0.741 \\
\hline 60 & $112.93 \pm 10.40$ & $113.63 \pm 6.98$ & 0.760 \\
\hline 70 & $112.53 \pm 10.70$ & $115.5 \pm 6.17$ & 0.193 \\
\hline 80 & $112.76 \pm 10.75$ & $116.03 \pm 5.65$ & 0.146 \\
\hline 90 & $113.13 \pm 10.15$ & $115.7 \pm 4.69$ & 0.210 \\
\hline
\end{tabular}

Comparison of Systolic Blood Pressure between Two Groups

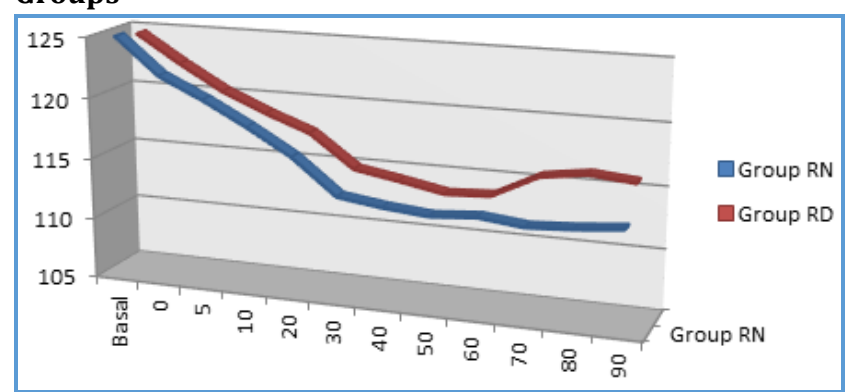

Comparison of Diastolic Blood Pressure between Two Groups

\begin{tabular}{|c|c|c|c|}
\hline DBP (mmHg) & Group RN & Group RD & P Value \\
\hline BASAL & $77.23 \pm 11.76$ & $75.56 \pm 10.33$ & 0.562 \\
\hline 0 & $73.23 \pm 10.74$ & $72.73 \pm 9.65$ & 0.850 \\
\hline 5 & $72.63 \pm 9.74$ & $72.33 \pm 8.96$ & 0.901 \\
\hline 10 & $70.7 \pm 9.18$ & $71.13 \pm 9.80$ & 0.860 \\
\hline 20 & $69.13 \pm 9.07$ & $69.53 \pm 10.52$ & 0.875 \\
\hline 30 & $69.53 \pm 7.76$ & $68.83 \pm 8.87$ & 0.746 \\
\hline 40 & $69.76 \pm 7.24$ & $69.8 \pm 9.43$ & 0.987 \\
\hline 50 & $69.2 \pm 7.16$ & $67.8 \pm 8.22$ & 0.484 \\
\hline 60 & $68.5 \pm 7.28$ & $67.9 \pm 7.71$ & 0.757 \\
\hline 70 & $69.13 \pm 6.83$ & $69.36 \pm 7.92$ & 0.903 \\
\hline 80 & $68.16 \pm 6.47$ & $68.2 \pm 8.75$ & 0.986 \\
\hline 90 & $67.03 \pm 7.60$ & $66.9 \pm 8.90$ & 0.954 \\
\hline
\end{tabular}


Comparison of Diastolic Blood Pressure between Two Groups

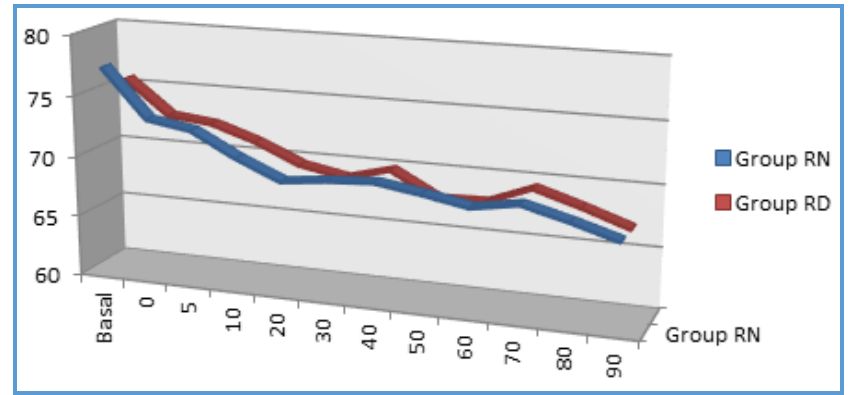

Complications during the Study

\begin{tabular}{|c|c|c|c|}
\hline Adverse Effect & \multicolumn{2}{|c|}{ Group } & P Value \\
\hline & $\begin{array}{c}\text { Group } \\
\text { RN N (\%) }\end{array}$ & $\begin{array}{c}\text { Group RD } \\
\text { N (\%) }\end{array}$ & \\
\hline $\begin{array}{c}\text { Evidence of } \\
\text { bradycardia }\end{array}$ & $4(10 \%)$ & $7(17.5 \%)$ & 0.212 \\
\hline $\begin{array}{c}\text { Evidence of } \\
\text { hypotension }\end{array}$ & $9(22.5 \%)$ & $15(37.5 \%)$ & 0.222 \\
\hline Others & $16(40 \%)$ & $4(10 \%)$ & 0.0038 \\
\hline
\end{tabular}

Complications during the Study

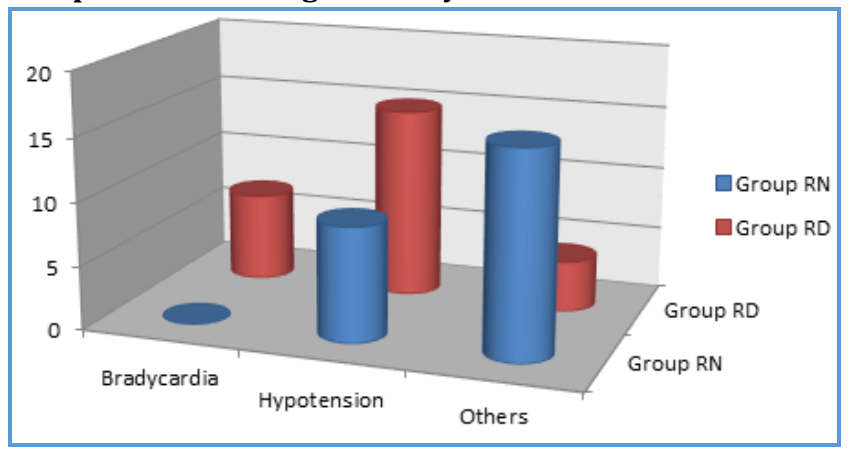

\section{DISCUSSION}

Orthopaedic surgeries and lower limb surgeries are usually associated with perioperative pain, which is a potent trigger for the stress response and autonomic system and is thought to be an indirect cause of various adverse effects like myocardial ischaemia, infarction, thromboembolic phenomena, impaired pulmonary function, ileus, fatigue, muscle catabolism, postoperative infection, and postoperative confusional states.

Epidural anaesthesia and analgesia is considered by many as the gold standard technique for major surgery. It has the potential to provide complete analgesia for as long as the epidural is continued. Epidural techniques are particularly effective at providing dynamic analgesia allowing the patient to mobilise and resume normal activities unlimited by pain. It also improves the postoperative outcome and attenuates the physiologic response to surgery in particular significant reduction in pulmonary infections, pulmonary embolism, ileus, acute renal failure, and blood loss.

A newly introduced long-acting amide linked local anaesthetic, bupivacaine congener "ROPIVACAINE" was registered for use in 1996 (Whiteside JB 2001), but registered for use in India in 2009 only.

Ropivacaine is a pure ' $S$ ' enantiomer with low lipid solubility, which blocks nerve fibers involved in pain transmission (A Delta and C fibers). Ropivacaine has less motor blockade and shorter duration than bupivacaine (Scott et al 1995, Markham 1996, Zarie et al 1996).

Dexmedetomidine is a highly selective $\alpha-2$ adrenergic agonist with an affinity of eight times greater than that of clonidine. The anaesthetic and the analgesic requirements get reduced to huge extent by the use of this adjuvant because of its analgesic properties and augmentation of local anaesthetic effects as it causes hyperpolarisation of nerve fibres by altering transmembrane potential and ion conductance at locus coeruleus in brain stem.

The results of the present study show that supplementation of epidural ropivacaine with dexmedetomidine significantly prolongs the duration of sensory and motor block with improved quality of postoperative analgesia as compared to ropivacaine alone. The mechanism by which $\alpha-2$ adrenergic agonists prolong the motor and sensory block of local anaesthetics maybe an additive or synergistic effect secondary to the different mechanisms of action of local anaesthetics. Dexmedetomidine act by binding to the presynaptic C-fibers and postsynaptic dorsal horn neurons.

They produce analgesia by depressing the release of $\mathrm{C}$ fibre transmitters and by hyperpolarisation of postsynaptic dorsal horn neurons. The complimentary action of local anaesthetics and $\alpha-2$ adrenergic agonists accounts for their profound analgesic properties. The prolongation of motor block maybe the result of binding $\alpha-2$ adrenergic agonists to the motor neurons in the dorsal horn. The use of dexmedetomidine has been studied as an epidural adjuvant by various authors who have observed its synergism with local anaesthetics without any additional morbidity (Salgado PF et al, Bajwa SJS et al).7,8

In the present study, we used fixed dose and concentration of ropivacaine i.e. $16 \mathrm{~mL}$ of $0.75 \%$ ropivacaine in both the groups as the volume of the study drug because the influence of height and weight on the spread of epidural block is very little and usually not clinically relevant unless considering the extremes of the spectrum.

Time of onset of sensory block to T10 dermatome in Group RD (12.53 $\pm 4.17 \mathrm{~min})$ was found to be little earlier than Group RN (14.18 $\pm 6.02 \mathrm{~min})$ with a statistically nonsignificant $(\mathrm{P}>0.05)$.

These results were in concordance with the results of Salgado PF et al who observed similar results with $20 \mathrm{~mL}$ of $0.75 \%$ ropivacaine $(13.8 \mathrm{~min}$ ) and with $0.75 \%$ ropivacaine and $1 \mu \mathrm{g} / \mathrm{kg}$ dexmedetomidine (11.5 min).

However, in study done by Bajwa SJS et al using $1.5 \mu \mathrm{g} / \mathrm{kg}$ dexmedetomidine, onset at T10 dermatome was $8.52 \pm 2.36$ min.

The mean time taken to reach maximum sensory level in Group RN was 23.24 $\pm 5.971 \mathrm{~min}$ and in Group RD was $21.63 \pm 4.172 \mathrm{~min}$, which was almost comparable (p 0.122).

Bajwa SJS, et al in their study also observed a similar result (13.14 $\pm 3.96 \mathrm{~min})$ when dexmedetomidine was used as an adjuvant to ropivacaine. The epidural dexmedetomidine used in our study had shown comparable onset of Maximum Motor Block (27.34 \pm 5.970 min vs $25.73 \pm 4.172 \mathrm{~min}$ ) (p 0.123) with significantly Prolonged duration of Motor Block $(259.80 \pm 15.486 \mathrm{~min}$ vs $385.92 \pm 17.719 \mathrm{~min})(\mathrm{p}<0.001)$. Similar results were observed by Salgado PF et al and Bajwa SJS et al.

Total duration of motor block in Group RN was $259.80 \pm 15.86$ min while in Group RD was 385.92 \pm 17.719 
min $(\mathrm{p}<0.001)$, which is almost similar to the results of Salgado PF et al (300 min) and Brown D et al ${ }^{9}$ (220 min).

Time for two segment regression of sensory block to T10 dermatome was earlier in Group RN (277.58 $\pm 17.66 \mathrm{~min})$ when compared to Group RD (404.18 $\pm 17.93 \mathrm{~min})$.

Similarly, comparable time $(237 \pm 65 \mathrm{~min})$ was observed by Brown D et al using $20 \mathrm{~mL}$ of $0.5 \%$ ropivacaine.

In the present study, patients remained haemodynamically stable in both groups and incidence of bradycardia and hypotension was comparable at all measured intervals, which reaffirms the established effects of $\alpha-2$ agonists in providing a haemodynamically stable perioperative period.

\section{CONCLUSION}

Our study reveals that $16 \mathrm{~mL}$ of ropivacaine $0.75 \%$ along with dexmedetomidine when administered epidurally provides adequate anaesthesia for lower extremity surgery.

Onset of sensory blockade is slightly faster with dexmedetomidine while the level of sensory block was comparable.

Ropivacaine + dexmedetomidine group had earlier onset of motor blockade with longer duration of motor block and more intense motor block as compared to ropivacaine alone.

The haemodynamic effects were comparable in both the drugs.

Hence, we can conclude that ropivacaine along with dexmedetomidine can be used successfully for epidural anaesthesia in lower extremity surgery.

\section{REFERENCES}

1. Ehrlich GE. Racemic mixtures: Harmless or potentially toxic. American Journal of Hospital Pharmacy 1992;49(9 suppl 1):S15-8.

2. Whiteside JB, Wildsmith JA. Developments in local anaesthetic drugs. Br J Anaesth 2001;87(1):27-35.

3. Scott DB, Lee A, Fagan D, et al. Acute toxicity of ropivacaine compared with that of bupivacaine. Anaesth Analg 1989;69(5):563-9.

4. Markham A, Faulds D. Ropivacaine. A review of its pharmacology and its uses in regional anaesthesia. Drugs 1996;52(3):429-49.

5. Zaric D, Axelsson K, Nydahl PA, et al. Sensory and motor blockade during epidural analgesia with $1 \%, 0.75 \%$, and $0.5 \%$ ropivacaine-a double-blind study. Anaesth analg 1991;72(4):509-15.

6. Burm AG, Zimpfer G. Levobupivacaine versus extradural $\mathrm{S}(-)$ bupivacaine: comparison with racemic RSbupivacaine. Rev Bras Anaest 1997:47CBA.

7. Salgado PF, Sabbag AT, Silva PC, et al. Synergistic effect between dexmedetomidine and $0.75 \%$ ropivacaine in epidural anaesthesia. Rev Assoc Med Bras 2008;54(2):110-5.

8. Bajwa SJS, Bajwa SK, Kaur J. Dexmedetomidine and clonidine in epidural anaesthesia: a comparative evaluation. Indian J Anaesth 2011;55(2):116-21.

9. Brown D, Carpenter RL, Thompson GE, et al. Comparison of $0.5 \%$ ropivacaine and $0.5 \%$ bupivacaine for epidural anaesthesia in patients undergoing lower extremity surgery. Anaesthesiology 1990;72(4):633-6. 